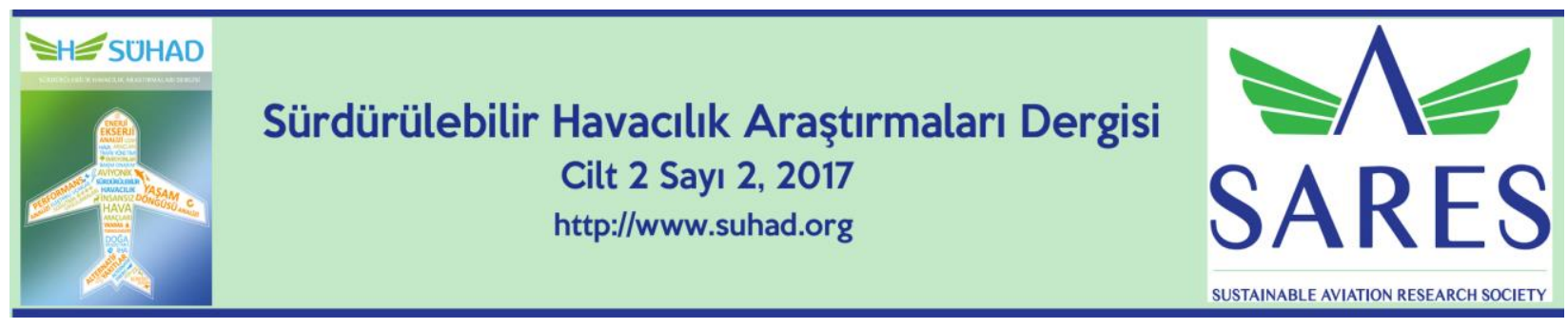

\title{
UÇAKLARDA BUZLANMA VE BUZLANMAYI ÖNLEYECEK YÖNTEMLER
}

\author{
Derya ÜNLÜ ${ }^{1}$, Nilüfer DURMAZ HILLMIOĞLU² \\ 1Dr. Derya Ünlü, Kocaeli Üniversitesi, Kimya Mühendisliği Bölümü, Kocaeli, derya.unlu@kocaeli.edu.tr \\ 2Prof. Dr. Nilüfer Durmaz Hilmioğlu, Kocaeli Üniversitesi, Kimya Mühendisliği Bölümü, Kocaeli, niluferh@kocaeli.edu.tr \\ DOI: $10.23890 /$ SUHAD.2017.0204
}

\section{ÖZET}

Uçakların kanatları üzerinde ki kar ve buz birikintileri uçuş performansını etkileyerek uçuşun elverişsiz hale gelmesine sebep olur ve kalkış yapmasını engeller. Bu sebeple buzlanma havacılık sektöründe önemli bir meteorolojik tehlikedir. Uçuş yüksekliği, hava koşulları, nem, sıcaklık gibi çevresel faktörler buzlanmayı önemli derecede etkiler. Buzlanma yolcuların hayatını tehlikeye sokacak sonuçlara sebep olabileceği için tehlikeli bir durumdur. Dolayısıyla buzlanma olayının sebepleri, neden olduğu olumsuz sonuçlar ve buzlanmayı engelleme veya buzlanmanın olumsuz sonuçlarını ortadan kaldırma çalışmaları hem insan hayatı bakımından hem de teknolojik açıdan önemli bir yere sahiptir. Bu çalışmada buzlanma oluşumunu ortadan kaldırmak için kullanılan buzlanma önleyici ve engelleyici kimyasallar, yapı malzemeleri araştırılmıştır.

Anahtar Kelimeler: Buzlanma, mat buz, parlak buz, uçak.

\section{ICING IN AIRCRAFT AND METHODS FOR PREVENTING ICING}

\begin{abstract}
Snow and ice accumulations on the wings affect the flight performance of plane, the flight becomes unfit and this ice accumulation prevents the taking off the plane. For this reason, icing is an important meteorological hazard in the aviation industry. Environmental factors such as flight altitude, weather conditions, humidity, temperature affect the icing significantly. Icing is dangerous for the passengers due to the flight effects. Therefore, the reasons of the icing, the negative consequences of icing and the efforts for the preventing the icing are both of important for the human life and technological approaches. In this study, icing and the methods of anti-icing and de-icing were investigated.
\end{abstract}

Keywords: Icing, dull ice, glare ice, aircraft

\section{GíRiş}

Buzlanma, hava sıcaklığı donma noktasının altına indiğinde veya havadaki nemin yağış olarak yeryüzüne indiği durumlarda beklenir. Bu yağış, yağmur veya kar seklinde olabilir. Ayrıca sisin yoğunlaşması ile de buzlanma oluşabilir. Buzlanma çoğunlukla çok soğuk hava şartlarında meydana gelir. Ayrıca buzlanma, uçak yüzeyinin sicaklığı donma sıcaklığının altında ise ve havada nem varsa oluşabilir. Yağmur damlacıkları, donma noktasından düşük sıcaklıktaki uçak yüzeyi ile temas ettiğinde, uçağın kanatları üzerlerinde buzlanma meydana gelir (Çakıc1, 2015; Fakorede vd., 2016).
Uçağın temiz yüzeye sahip olması performansında oldukça önemli etkiye sahiptir. Kar ve buzun uçak yüzeyinde toplanması uçağın ağırlığını arttır. $\mathrm{Bu}$ durum, sürüklenme kuvvetini artırır ve uçağa etki eden kaldırma kuvvetini azaltır ve uçağın harcadığı güç artar. Bu yüzden uçağın yüzeyinde kar ve buzun bulunduğu durumlarda uçuş yapılması güvenilir değildir.

Artan uçak ağırlığı, kanadın aerodinamik şeklini bozarak taşıma kuvvetini azaltır. Bu da uçağın havada tutunma hızının artmasına yol açar. Kanatçıklar ve irtifa dümeni gibi uçuş kontrol yüzeylerinin donması ve kuyruk bölgesinde buzlanma uçağın kontrolünü zorlaştırır (Jung vd., 2015, Wang vd., 2014). 
Uçaklarda kullanılan piston motorların, gaz türbinlerinin hava giriş kanallarında oluşan buzlanma ciddi bir problemdir. Kanalları tıkayarak motora giren hava miktarının azalmasına sebep olur. $\mathrm{Bu}$ da motorun hasar görerek güç kaybetmesine hatta durmasına bile sebep olabilir. Ayrica pervaneli hava taşıtlarında pervanelerin buzlanması dengeyi bozarak sarsıntılar yol açar.

Uçak yüzeylerinde çeşitli amaçlarla bulunan hava delikleri vardir. Buzlanma bu deliklerin de tıkanmasına neden olur. Bu durumda hava hızı göstergelerini içeren cihazlarda yanlış değerler gösterir, bu da büyük kazalara neden olabilir. Temiz hava girişlerinin sağlandığı hava kanallarının, yakıt sistemindeki hava deliklerinin tıkanması da önemli sorunlara yol açabilir. Ayrıca kokpit camının buzlanarak görüşü bozması, kalkış ve inişleri zorlaştırır (Boduroğlu, 2014).

Buzlanmanın sebep olabileceği tüm bu problemler, uçaklarda buz kontrol sistemlerinin önemini vurgular. Bu çalışmada uçaklarda buzlanma olayı, buzlanmanın sebepleri ve buz giderme sistemleri incelenmiştir.

\section{BUZ OLUŞUMU}

Uçakta buz oluşumu şu şartlar altında gerçekleşir:

- Uçak yüzeyinde sıvı halde suyun varlığı,

- $\quad 0^{\circ} \mathrm{C}^{\prime}$ nin altında atmosfer sıcaklığ 1

- $\quad 0^{\circ} C^{\prime}$ nin altında uçak yüzeyinin sıcaklığı

Uçak yüzeyinde meydana gelen buzlanma hava akışını bozar. Uçağın yükselme gücü azalır, ağırlık ve sürtünme artar. Buzlanma uçağın pitot tüpü, motor, kanat ve kuyruk gibi uçağın yapısal parçalarına zarar verir. Uçağın inişi ve kalkışı esnasında sorunlara neden olur. Ayrica yakitın da buzlanması yakıt kanallarını kapatır.

\subsection{Buz Çeşitleri}

Uçaklarda iki çeşit buzlanma meydan gelir. Bunlar mat buz ve parlak buz olarak adlandırılır. Küçük su damlaları hızlı bir şekilde donarlar ve havayı içerisinde hapsederler. Oluşan bu buz-hava karışımı mat buz olarak adlandırılır. Mat buz $0^{\circ} \mathrm{C}$ 'nin altındaki sıcaklıklarda oluşur. Buzun görünümü oldukça mattır, yüzeyde tutunamaz, bu sebeple kanatların üzerinde fazla yayılamaz. Mat buzlanma dışa doğru keskin bir burun şeklinde çıkıntı yapar. Mat buz ve parlak buzun yüzey üzerinde oluşturduğu şekil, Şekil 1' de verilmiştir. Mat buz, buzlanmayı önleyici ya da giderici sistemlerle önlenebilir.

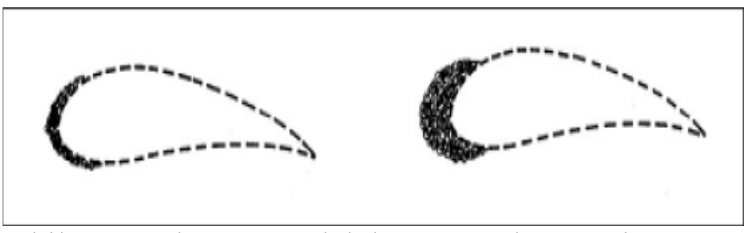

Şekil 1: Mat buz ve parlak buzun uçak yüzeyi üzerinde aldığı şekil

Büyük su damlaları kanat ile temas ettiğinde bir bölümü donarken, donmadan kalan bölüm kanattan akarken donar. İçinde hava kabarcığı kalmayan su damlacığ́ yüzeye iyi tutunma özelliğine sahiptir. Bu buz çeşididir "parlak buz" olarak adlandırılır. Şeffaf, yoğun ve sert bir yapıya sahiptir. Şekil 2'de parlak buz görülmektedir.

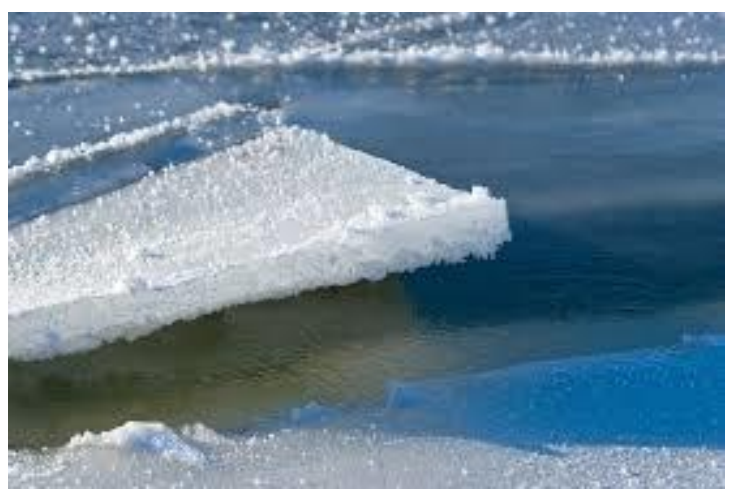

Şekil 2: Parlak buz görünümü

Soğuk hava koşullarında uçak kanatlarının üst yüzeylerinde oluşan parlak buz tabakası kanatların alt yüzeylerinde de buzlanmaya neden olmaktadır.

Parlak buz uçak yüzeyinde geniş bir alana yayılarak yüzeyin şeklini alır. Yüzeye güçlü bir şekilde tutunur ve yüzeyden ancak kırılma ile uzaklaşır. Parlak buzun kanatlar üzerinde oluşumu motorunu arkasında bulunan uçaklar için oldukça tehlikelidir. Uçağın kalkışı ve inişi sırasında buz kırılır ve kanattan ayrılarak motor tarafina geçer ve buzun büyüklüğüne bağlı olarak motorda hasar oluşmasına neden olur. Parlak buz çoğunlukla $0^{\circ} \mathrm{C}$ ile $-10^{\circ} \mathrm{C}$ arasında oluşur. En tehlikeli buzlanma türüdür. Önlenmesi en zor buzlanma şeklidir (Demirgüç, 1955).

Kontroller esnasinda saydam buzu tespit etmek oldukça güçtür. Zayıf ışık altında ya da kabinden görülmesi mümkün değildir. Oluşan buz motor tipine göre bazı uçaklar için büyük tehlike oluşturmaktadır. Uçağın kalkışı ve inişi esnasında kanat üzerine yapışan buz, esneme dolayısıyla kırılır. Kırılan bu buz tabakaları motorun içine akar motorda hasar oluşturabilir. 


\section{BUZLANMANIN UÇUŞA ETKILERİ}

Buzlanma uçuşu olumsuz etkileyen ve güvenliği düşüren önemli bir olaydır. Buzlanma uçak tiplerine göre farklı etkilere sahiptir. Uçak yüzeyinde ve kanatlarda buz birikimi uçağın ağırlığının artmasına, güç ve hız kaybına neden olur. Uçağın kararlığını ve kontrolünü bozar ve performansını düşürür. Kanattaki buzlanma kanadın şeklini bozar ve taşıma kuvvetini azaltır. Bunun yanında uçak yüzeyinde, havalandirma sistemlerinde ve yakıt sistemlerinde bulunan hava deliklerinin buzlanması da oldukça tehlikeli bir durumdur ve büyük kazalara sebep olabilir.

Buzlana, sürüklenme kuvvetinde de artsşa sebep olur. $\mathrm{Bu}$ durum uçağın hızında düşüşe, yakıt tüketiminde artışa neden olur. Sürükleme kuvveti ile kaldırma kuvveti arasındaki ilişki Şekil 3'te verilmiştir (Paraschivoiu ve Saeed, 2005).

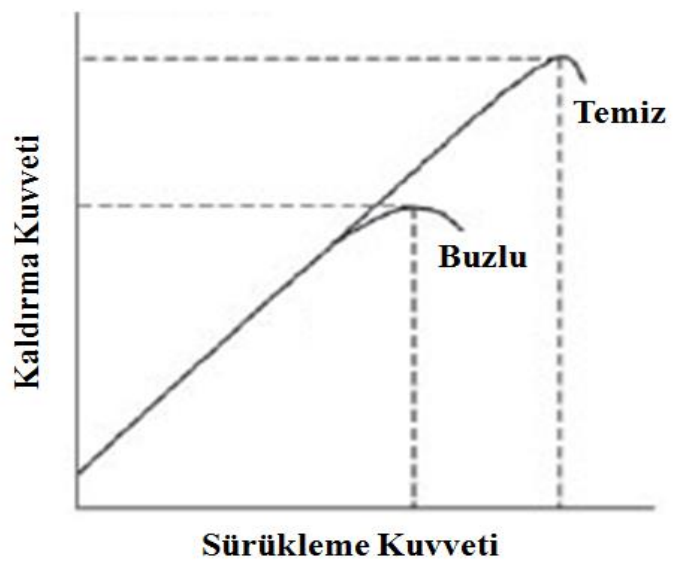

Şekil 3: Uçağa etki eden kaldırma kuvveti ve sürüklenme kuvvetinin temiz ve buzlu yüzeyde değişimi

Buzlanma kaldırma kuvvetinde önemli azalmaya sebep olur. Buzlanma miktarına bağlı olarak maksimum kaldırma kuvveti katsayısı $\left(\mathrm{CL}_{\max }\right)$ azalır. Çok az bir buzlanma dahi $\mathrm{CL}_{\max }$ değerinde düşüşe sebep olur. Şekil 4'te bir ATR Uçağının kaldırma kuvveti katsayısının buz kalınlığı ile değişimi gösterilmiştir (www.atraircraft.com).

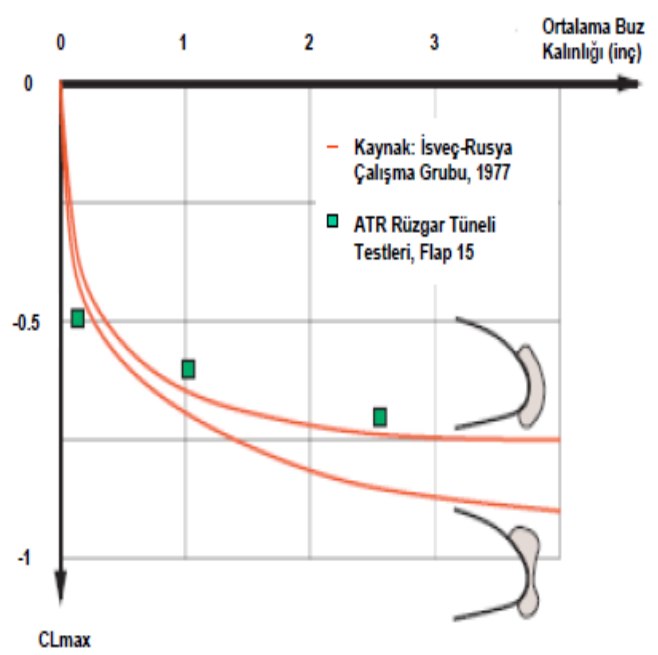

Şekil 4: ATR Uçağının kaldırma kuvveti katsayısının buz kalınlığı ile değişimi

Uçağın kanadının yanı sıra kuyruk bölgesinde de buzlanma görülebilir. Bu bölgedeki buzlanma uçağın burun aşağı hareketine sebep olur. Şekil 5 'te uçağa etki eden kuvvetlerin buzlanmanın uçağa etkisi gösterilmiştir. $\mathrm{Bu}$ durum iniş sırasında sorunlara neden olmaktadır (Boduroğlu, 2014).
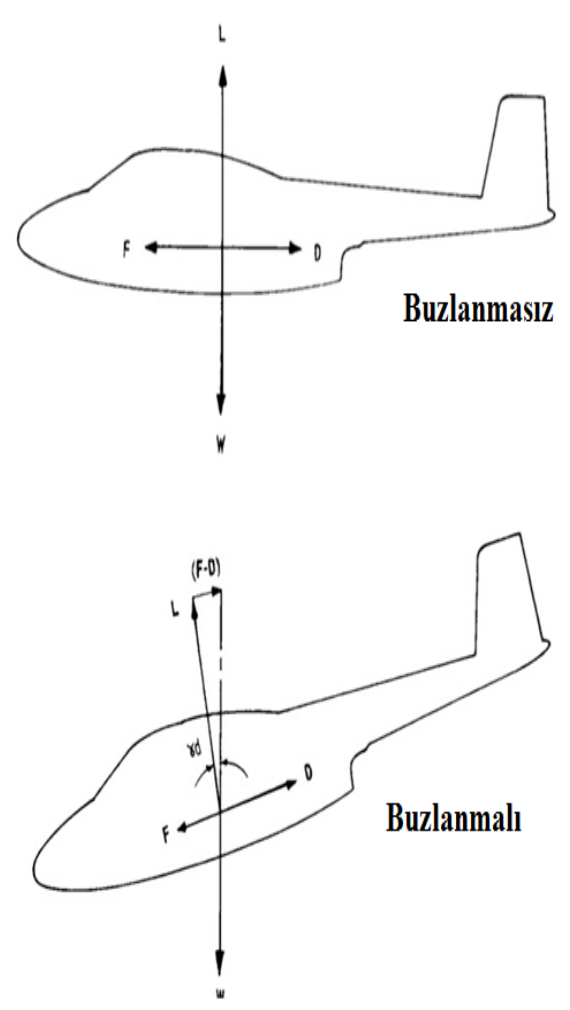

Şekil 5: Uçağa etki eden kuvvetlerin buzlanma ile birlikte değişimi 


\section{BUZLANMAYI ETKİ EDEN FAKTÖRLER}

\subsection{Sicaklık}

0 ile $-40^{\circ} \mathrm{C}$ sıcaklıkları arasında buzlanma görülebilen sıcaklık aralığıdır. $-25 \mathrm{oC}$ 'ye kadar yoğun olarak buzlanma görülürken, $30^{\circ} \mathrm{C}$ 'nin üzerinde ender buzlanma görülür. $30.000 \mathrm{ft}$ yüksekliğe kadar buzlanma görülebilir.

\subsection{Su Miktarı}

Bulutta bulunan su miktarı buzlanma oranının belirlenmesinde oldukça önemlidir. Bulut ne kadar alçak olursa ve sıcaklığı ne kadar yüksek olursa bulutun içindeki su miktarı da o kadar fazla olur. Soğuk su damlacıklarının sayısının artması da buzlanma olasılığını arttırır.

\subsection{Damlacik Boyutu}

Damlacık boyutu buzlanmada önemli bir etkiye sahiptir. Boyut büyüdükçe buzlanma da artar.

\subsection{Birikim}

Uçak yüzeyinde biriken su damlacıkları arttıkça bulanmanın etkinliği artmaktadır. Burada uçak yüzeyinin yapısı ve büyüklüğü su damlacıklarının tutunmasinı belirler.

\subsection{Aerodinamik Isınma}

Aerodinamik 1sınma artıkça buzlanma azalır. Aerodinamik 1sınma uçağın hızına ve yükseliğine göre değişri. Uçak üzerinde buzlanma meydana gelemsi için sıcaklığın $0^{\circ} \mathrm{C}$ altında olması gerekir.

\subsection{Bulutluluk}

Bulutun üzerine yükselmek buzlanma olasılığııı azaltır. Bulutların alt tarafında sıcaklık artıkça buzlam riski de oluşur (Çamalan, 2011).

\section{BUZLANMAYI ENGELLEME YÖNTEMLERİ}

\subsection{Buz Önleme Sistemleri (Anti-Icing)}

Uçaklarda buzlanmayı önlemek için; termal, elektrikli ve kimyasal buz önleme sistemleri kullanılmaktadır.

Termal buz önleme sistemlerinde sicak hava gaz türbinli uçaklarda kompresörlerinden, Pistonlu motorlu uçaklarda ise egzoz gaz isitıcılarından sağlanır. Bu sıcak hava ile kanat, kuyruk ve motor hava girişi bölgelerinde buzlanma önlenir.

Uçakların birçoğunda ise buzlanmayı önlemek için elektrikli 1sıtma kullanılmaktadır. $\mathrm{Bu}$ yöntem buzlanmadan korumak için bir nesneden geçen akım üzerinde yayılan Joule isısının kullanımı temellidir. Buzlanma ihtimalinin olduğu yerler elektrik akımı ile ssıtılarak buzlanmanın önlenmesi sağlanır. Yolcu uçaklarındaki tuvalet ve lavabolarda su hatlarının donmasını engellemek için de elektrikli 1sitıcılardan yararlanılmaktadır. Aynı şekilde Kokpit camlarının buzlanmasını önlemek için de elektrikli 1sıtma kullanılmaktadır. Ancak bu metotlar ilave güç tüketimi ve pahalı cihaz gerektirir (Boinovich ve Emelyanenko, 2013).

Buzlanmayı önlemek için kullanılan bir diğer yöntemde kimyasal yöntemdir. $\mathrm{Bu}$ yöntem sudan daha düşük kristalizasyon sicaklığına sahip sulu çözeltili sıvıların kullanımını içerir. İzopropil alkol, etilen glikol veya alkol karışımları kullanılarak buzlanma önlenilmektedir. Bu kimyasal maddelerin kullanımı uçak üzerindeki suyun donma noktasını düşürür, yüzeyi kayganlaştırarak yüzey üzerinde buz oluşumunu önler. Bu buz önleyici kimyasallar kokpit camlarına, pervanelere ve karbüratörlere uygulanmaktadır (Murphy vd., 2015, Sanderson, 1997).

\subsection{Buz Giderme Sistemleri (De-Icing)}

Uçağın kanat ve kuyruk yüzeylerinde buz önleme yerine buz giderme sistemlerinin kullanımının daha etkili olduğu belirlenmiştir. Bu yüzden başlangıçta buz oluşumuna izin verilir ve sonrasında buz kırılarak buzun giderilmesi gerçekleştirilir. Buz giderme sisteminde buz önleyici sistemlerin sebep olduğu çözülen buzlardan akan suların tekrar donup buz oluşturması ve uçuşu olumsuz etkileme gibi olumsuz özellikleri engellenmiş olunur (Paraschivoiu ve Saeed, 2005).

Pnömatik buz giderme sistemi olarak adlandırılan buz giderme sistemlerinde kanat ve kuyruk bölgelerine kauçuk kaplamalar yerleştirilir. $\mathrm{Bu}$ kaplamalar, tüplerden meydana gelmektedir. Tüpler şişirilerek hava ile doldurulup sonrasında boşlatılabilme özelliğin sahiptir. Şekil 6'da pnömatik buz giderme sistemi örneği verilmiştir.

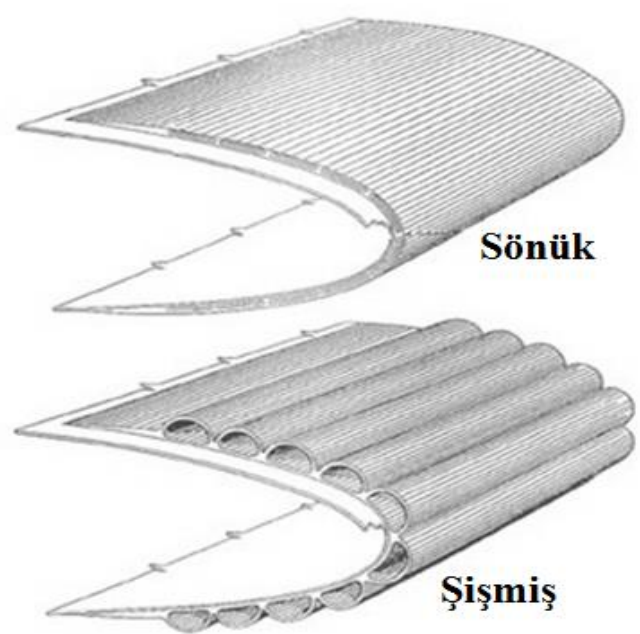

Şekil 6: Pnömatik buz giderme sistemi 
Pervaneli uçaklarda ise kauçuk kaplamaların içine 1sitıcı kablolar konulur. Bu kablolara gelen elektrik akımı kauçuğun 1sınmasını sağlar ve oluşan buzun erimesi sağlanır. Rüzgârın etkisiyle ya da merkezkaç kuvveti ile de buz bulunduğu yüzeyden uzaklaştırılır. Uçaklar karlı kış günlerinde hangarlardan çıkarıldıklarında yüzeylerinde buzlanma görülebilir. Buzlanmayı ortadan kaldırılmak için kullanılan yöntemler aynı zamanda tekrar buzlanma olasılığını da ortadan kaldırmalıdır. Şekil 7'de uçak yüzeydeyken buz giderme yöntemi gösterilmiştir.

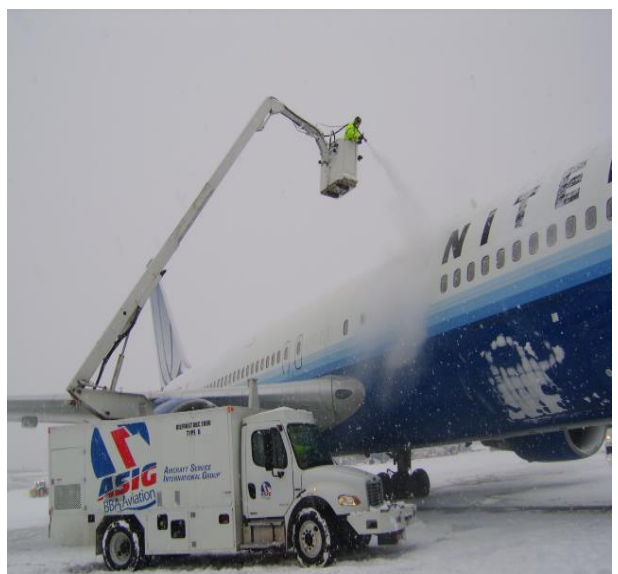

Şekil 7: Uçak yüzeydeyken buz giderme yöntemi

Tüm bu metotlar atmosferik buzlanma koşulları altında buz birikimini azaltmak için kullanılır ancak bazı durumlarda yetersiz kalmaktadır. Ayrıca bu yöntemler aktif personel kullanımı ve enerji ve kimyasal tüketimi gerektirir ve kullanılan kimyasal ve harcanılan enerji çevreye zarar verir. Bu yöntemlere alternatif olarak buzu sevmeyen, buz tutmayan yüzeylerin kullanımı ilgi çekici yöntemlerden biri olmaktadır. Bu yaklaşımın verimi suyun yüzeyde birikimini azaltmak için su itici yüzey özelliklerine bağlıdır. Buz tutmayan yüzeyler oluşan buzun, karın veya donun düşük adhezyonu ile karakterize edilir (Boinovich ve Emelyanenko, 2013).

Buz tutmayan yüzeylerin kullanımının yanında yüzeylerin anti-icing kaplama yöntemi bir diğer ilgi çekici yöntemdir. Yüzey topografisini modifiye ederek buz birikimini ve oluşumunu engeller. Antiicing stratejisinde de suyu iten ve su damlacıklarının yapışmasını engelleyen kaplamalar kullanır (Jung vd., 2015).

Bir diğer buz giderme sistemi elektriksel impulslar ile buz giderme sistemidir. Elektriksel impulslar ile buz giderme mekanik bir yöntemdir, çalışma prensibi Şekil 8'de gösterilmiştir. Trafo ve doğrultucu köprü vasıtasıyla, güçler DC'ye dönüşür ve kapasitöre voltaj tedarik eder. Kondansatör ayarlanan değeri aldığında, şarj devresinin güç bağlantısı kesilir. Daha sonra tiristör (SCR), kondansatörün bobin boyunca deşarj olmasını sağlamak için tetiklenir. Bobinde akan anlık akım nedeniyle manyetik alan oluşmakta ve bobinde hızlı bir şekilde azalmaktadır, böylece metal yüzeyde girdap akımına neden olmaktadır. Bu nedenle, bobin ile metal yüzey arasında darbe kuvveti oluşur. İmpuls kuvveti yüzeyin küçük amplitüdün elastik deformasyonuna ve buzun kırılması için yüksek ivmelenme hareketine neden olur. Sonrasinda kirılan buzlar havaya uçurulur.

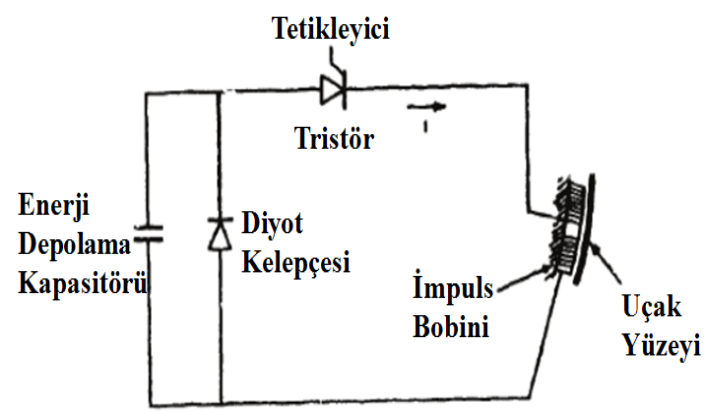

Şekil 8: Elektro-impuls sistemi temel devresi

Tristör (SCR), devrenin tetik gerilimini veya tetikleme süresini ayarlayarak devreye sokmasını veya bağlantısını kesmesini sağlayan kontrol devresi için kullanılır. SCR'nin doğası gereği diyot özellikleri vardır; döngü akımı RLC tepkisinin ilk pozitif döngüsünü izler. Bu, kapasitörün ters şarj edilmesiyle sonuçlanır. Kondansatörlerin polaritesi vardır ve bu tür ters şarj, kondansatörü önemli derecede azaltır. Bu nedenle kondansatörün üzerine bir sıkıştırma diyot yerleştirilir (Fan ve Shinan, 2011).

Mekanik buz çözme teknolojilerinden biri olan Ultrasonik Kilavuzlu Dalga buz giderme teknolojisi, kolay değişim ve bakım özellikleri kadar, hafifliği, düşük maliyeti, enerji tüketiminde ciddi azalma gibi özelliklere sahiptir. Ultrasonik teknikler kapsamlı olarak incelenmiş ve uçak buzlanma araştırmaları için uygulanmıştır. Ultrasonik dalga, buzu gidermek için uçak yüzeyinde yüksek frekanslı titreşim gerçekleştirir. $\mathrm{Bu}$ yöntem, ultrasonik buz çözme teorisi, piezoelektrik malzemeler ve dönüştürücüler, buz çözücü sistem tasarımı ve enerji tasarrufu gibi çeşitli bileşenleri içerir (Wang vd., 2017).

\section{SONUÇ}

Havacılık uygulamalarında buzlanma önemli bir problemdir. Uçuş performansını düşürerek uçuşu tehlikeli hale getirir. Sicaklık, nem gibi atmosfer koşulları buzlanmanın derecesini etkileyen önemli faktörlerdir. Buzlanma uçuş iptaline ya da uçuşlarda gecikmelere neden olur. Çünkü buzlanma uçağın aerodinamik kuvvetlerini etkiler. Sürüklenmeyi arttırarak kaldırmayı azaltır. Uçuş esnasında meydana gelebilecek olumsuz koşulları önlemek için buz 
önleyici ya da giderici işlemler uygulanmaktadır. Bu çalışmada buzun oluşumuna sebep olacak koşullardan bahsedilmiştir. Ardından buzlanma çeşitleri açıklanmıştır. Mat buz ve parlak buzun oluşumu ve uçuşa etkileri incelenmiştir. Buzlanmaya etki eden faktörler listelenmiştir. Buzlanmayı engellemek için kullanılan buz giderici ve buz önleyici sistemler açıklanmıştır. Ayrıca alternatif olarak son yıllarda kullanılan kaplama yöntemlerinden söz edilerek çalışma sonlandırılmıştır.

\section{KAYNAKLAR}

Boduroğlu K., (2014), Uçaklarda Aeorodinamik Yapısal Ve Sistemsel Problemlere Yol Açan Donma Probleminin İrdelenmesi, Yüksek Lisans Tezi, Yıldız Teknik Üniversitesi, Fen Bilimleri Enstitüsü, İstanbul.

Boinovich L.B., Emelyanenko A.M., (2013), Antiicing potential of superhydrophobic coatings, Mendeleev Communication, 23, 3-10 .

Çakıcı A., (2005), Uçaklarda buzlanma ve pervaneli uçaklarda buz giderme sisteminin değerlendirilmesi üzerine bir araştırma, Yüksek Lisans Tezi, Gazi Üniversitesi, Fen Bilimleri Enstitüsü, Ankara.

Çamalan İ., (2011), JAA ATPL Eğitimi (Meteoroloji), Meteoroloji Mühendisi Havacılık Meteorolojisi Şube Müdürlüğü 2011.

Demirgüç, Z., (1955), Uçaklarda Buzlanma ve Korunma Metodları, İstanbul Teknik Üniversitesi Matbaası, İstanbul.

Fakorede O., Feger Z., Ibrahim H., Ilinca A., Perron J., Masson C., (2016), Ice protection systems for wind turbines in cold climate: characteristics, comparisons and analysis, Renewable and Sustainable Energy Reviews, 65, 662-675.

Fan G., Shinan C., (2011), Design Test of ElectroImpulse De-icing Systemof an Aircraft, 2nd International Conference on Artificial Intelligence, Management Science and Electronic Commerce (AIMSEC), 3918-3921.

Icing Manual, (2003), ATR Training Center, Toulouse, www.atraircraft.com, (Ziyaret Tarihi: 31.08.2017).

Jung M., Kim T., Kim H.,, Shin R., Lee J., Lee J., Lee J., Kang S., (2015), Design and fabrication of a large-area superhydrophobic metal surfacewith anti-icing properties engineered using a top-down approach, Applied Surface Science, 351, 920926.

Murphy C., Wallace S., Knight R., Cooper D., Sellers T., (2015), Treatment performance of an aerated constructed wetland treating glycol from de-icing operations at a UK airport, Ecological Engineering 80,117-124.

Parachivoiu, I., and Saeed, F., Aircraft Icing, Wiley, New York, 2004, pp. 1-24.

Sanderson J., (1997), A\&P Technician Airframe Textbook, Inc., USA.

Wang Y., Hudson N.E., Pethrick R.A., Schaschke C.J., (2014), Poly(acrylic acid)-poly(vinyl pyrrolidone)-thickened water/glycol de-icing fluids, Cold Regions Science and Technology, 101, 24-30.

Wang Y., Xu Y., Huang Q., (2017), Progress on ultrasonic guided waves de-icing techniques in improving aviation energy efficiency, Renewable and Sustainable Energy Reviews, 79, 638-645. 